\title{
Strategy for higher education
}

Richard Pearson

Modest increases in government spending on universities announced recently do nothing to fulfil the urgent need for a long-term strategy for higher education.

IT is now 18 months since the government published its consultative Green Paper on the future of higher education. Since then higher education has staggered on, responding to piecemeal evolution of a policy, which until last month has mainly resulted in a tightening of the financial screw. November saw a slight improvement, however, with a small increase in the universities' budgets as part of the government's boost to public spending. Whether this signals a change of policy is not clear and the government's White Paper on the future of higher education still seems many months away. Higher education will remain in a state of crisis and policy decisions by students and institutions will have to be taken on an ad hoc basis until the government sets out a longterm strategy.

Although some academics still fear a threat to academic freedom, it is clearly right that the role and running of a higher education system costing the public purse over $£ 3,500$ million each year should be a matter for public debate and scrutiny. But it would be wrong to seek change through a series of partial solutions and short-term actions that cause damage in the long term, while providing no strategic direction for the future. Major unresolved issues include those of student numbers, subject balance, student finance, and academic salaries and resources.

In the past the driving force influencing the size of higher education has been student demand, and particularly the wishes of 18-year-olds. But, with a student population of about 500,000 , the United Kingdom has low participation rates in higher education by international standards especially by women in technological subjects, mature entrants and ethnic minorities. The proportion of entrants from working class homes, at under 10 per cent, has barely changed for a decade. Participation by these groups needs to be increased, both for social reasons and to broaden the quality and range of experience in the graduate population which is too narrowly based. Such an increase would counteract the reduced demand for places due to the expected fall in the number of 18 -year-olds in the period to 1995 . Demand for graduates is now at record levels and expected to increase significantly, and the longer term need is for a better educated and more skilled workforce.

These social and economic objectives of higher education need not be incompatible. For example, the labour market too needs higher education to have a broader base than is provided by simple reliance on vocational subjects, because employers need a broad cross-section of skilled and educated staff. In the vast majority of jobs and careers, indeed there is no close link with degree subject, so that one in three of current vacancies for graduates do not specify a degree subject. This allows flexibility in the provision of courses for the majority of places and responsiveness to student demand and other criteria when planning subject balance. It also allows rebuttal of the complaint that precise manpower planning does not work, because such accuracy is simply not needed.

There is, though, a need to improve the content and quality of many courses to encourage communication skills, team work, numeracy and literacy. In addition a clarification of which are truly vocational courses needs to be undertaken and a better understanding of employers' current and future needs for specialist trained graduates is required.

More students, better salaries to retain and attract good teachers and adequate, up-to-date resources all cost money. They cannot realistically be paid for by savings from a loan scheme to replace student grants. Industrial support by sponsoring students, donating equipment, funding research, paying for visiting lecturers and financing higher academic salaries, all help higher education as well as the recruitment and research of the firms themselves. There are no exact figures on the full extent of direct industrial support, but overall it is probably less than $£ 100$ million, or under 3 per cent of the higher education budget. Thus even the expected significant increases over the next decade will not be enough to relieve the burden on the public purse, though it will continue to make a valuable contribution in selected areas. While improvements in efficiency can also undoubtedly be achieved, the necessary improvements in higher education cannot be realized within a reducing budget; public financing has to be increased in real terms, not reduced.

A better way of distributing finite resources may be through the introduction of the two-year general degree, topped up by a two-year specialist degree. The first degree would be available to all; it would offer a broad-based curriculum and would attract a maintenance grant. Student demand could strongly influence subject balance as long as there were some core general subjects which would compensate for any over specialization in the schools. Such degree courses could offer far more flexible entry qualifications, which would allow more mature students and those from less conventional backgrounds to enter higher education.

There would then be a smaller number of places on second degrees which would be more specialized, focusing on particular disciplines. The balance would be determined more by national or occupational criteria, as already happens in subjects such as medicine and architecture, or by the need for advanced study, as is the case for postgraduate courses in the arts and many of the social sciences. These subjects would attract further grants, scholarships or industrial sponsorship in key areas of the labour market and loans could also be available. A critical factor in their implementation would be that all degree courses should follow this pattern otherwise the new two-year degree courses would be instantly dubbed second class.

Whatever the strategy for higher education - and the options are diverse there must be a long-term perspective and an improved planning framework, which would require better information about inputs, processes and outcomes. If market forces are to play a key role then participants have to be better informed: students about job prospects to help in the choice of subject and course, institutions about economic needs to tailor a proportion of the courses accordingly, and government in terms of deciding how much money to spend, and where and how to allocate it. All these groups require a better articulation of the longer-term relationship between economic and industrial needs and the provision of higher education, so that priorities can be considered, and flexibility built into the system to cope with uncertainty. The performance of higher education as a whole also requires regular monitoring and policies must respond to changing economic and social needs.

Whatever the complexion of governments in the next decade there is unlikely to be a significant increase in the funding of higher education. Piecemeal policy adjustments are likely only to reinforce the downwards spiral and inhibit a successful transition into the 1990s. A longer-term strategy is vital.

Richard Pearson is at the Institute of Manpower Studies, Mantell Building, University of Sussex, Falmer, Brighton BNI 9RF, UK. 